\title{
ANÁLISE DO PROCESSO DE ORGANIZAÇÃO DAS APRENDIZAGENS EM UMA ASSOCIAÇÃO DE COLETA SELETIVA
}

Maria de Lourdes Fernandes de Medeiros ${ }^{1}$ Niascara Valesca do Nascimento Souza ${ }^{2}$ Vanessa Elionara Souza Ferreira ${ }^{3}$ Valdemar Siqueira Filho ${ }^{4}$

Resumo: Este estudo tem como problemática geral verificar como são gerenciados os processos de aprendizagens, na transformação de resíduos de uma Associação de coleta seletiva, que promove a geração de trabalho e renda, inclusão social e cidadania para as pessoas envolvidas na gestão integrada dos resíduos sólidos. Foi delimitado como objetivo a análise dos processos de difusão do conhecimento, considerando-se a condição transitória das aprendizagens entre $o$ formal (organizacional) e o informal (necessidades pessoais e individuais). A metodologia da pesquisa empregada está fundamentada em uma abordagem qualitativa de natureza teórico-empírica, com realização de visita in loco, e como instrumento de coleta de dados, utilizamos a observação e a escuta sensível das narrativas da fundadora da Associação em entrevista aberta.

Palavras-chaves: Aprendizagem Organizacional; Coleta Seletiva; Transformação; Associação.

\footnotetext{
${ }^{1}$ Universidade Federal Rural do Semi-Árido - Programa de Pós-Graduação em Ambiente, Tecnologia e Sociedade. Departamento de Agrotecnologia e Ciências Sociais. E-mail: lourdesfernandes@ufersa.edu.br.

2 Universidade Federal Rural do Semi-Árido - Programa de Pós-Graduação em Ambiente, Tecnologia e Sociedade. Departamento de Agrotecnologia e Ciências Sociais. E-mail: niascara.souza@ufersa.edu.br. ${ }^{3}$ Universidade Federal Rural do Semi-Árido - Programa de Pós-Graduação em Ambiente, Tecnologia e Sociedade. Departamento de Agrotecnologia e Ciências Sociais. E-mail: vanessaelionara@ufersa.edu.br. ${ }^{4}$ Universidade Federal Rural do Semi-Árido - Programa de Pós-Graduação em Ambiente, Tecnologia e Sociedade. Departamento de Agrotecnologia e Ciências Sociais. E-mail: dema@ufersa.edu.br. Revbea, São Paulo, V.10, No 4: 114-135, 2015.
} 


\section{Introdução}

Um dos maiores desafios da sociedade moderna é a preocupação com o meio ambiente, já que este oferece condições essenciais para a sobrevivência e evolução dos seres vivos. No Brasil, a questão do lixo, ou seja, dos resíduos sólidos produzidos nos ambientes urbanos e rurais, são considerados também como um problema econômico. Nesse sentido, Moura (2012 p. 48) afirma a "qualidade ambiental" é um bem público, válido em todo o país, e isto equivale dizer que a poluição em ambientes determinados tem o mesmo efeito na qualidade ambiental da nação, independentemente de onde ocorra. Nessa dimensão, esse fenômeno considerado global prejudicaria o desenvolvimento econômico do país, para a autora, surge como um processo de não investimento do capital natural, ou incentivo ao consumo, refletindo assim, no esgotamento e no uso sem proporções dos recursos renováveis, o que causa a acumulação dos resíduos e provoca: poluição, doenças e impactos ambientais de todo o tipo. Dentro dessa ótica, se torna um quadro típico dos países em desenvolvimento, mas, não invalida atitudes pró ativas e planejadas, com o objetivo de reduzir ou erradicar essa problemática, com a finalidade de manter um ambiente saudável e ecologicamente equilibrado para presentes e futuras gerações.

A coleta seletiva e a reciclagem são apresentadas, nesse contexto, como medidas introduzidas e divulgadas através de modelos de sustentabilidade economicamente viável. No entanto, o grande desafio é buscar instrumentos que levem a refletir sobre a importância de se estabelecer uma mudança de comportamento voltada para a reciclagem de materiais. Para, assim, se estabelecer uma postura sustentável e ambientalmente consciente em nosso país.

Nesse sentido, Zanginski, Lima e Costa (2009) defendem a aprendizagem organizacional como a interpretação e entendimento dos processos de ação, reflexão e ação. Para os referidos autores, as transformações ocorridas nas organizações reforçam o argumento de que o "conhecimento é um recurso" importante para o trabalhador, sendo este o maior ativo das instituições, se de fato isso implicar na alocação deste repertório de saber para o uso produtivo. Ao considerar o conhecimento como produto de origem intrínseca às pessoas da Associação, os possíveis resultados de um processo de aprendizagem organizacional não estão imbrincados apenas no provimento de resultados de desempenho com ganhos diretos de competitividade ou resultados financeiros positivos, mas na interpretação de todos os resultados e na geração de conhecimentos e competências, mesmo em situações em que o resultado de desempenho venha a ser considerado negativo.

A aprendizagem organizacional surge nesse processo como uma organização cultural complexa, permeada pela identidade como fator de coesão entre os membros do grupo. Essa identidade coletiva fortalece-se nos valores, atitudes e expectativas mediadas e compartilhadas entre toda a equipe. A gestão do conhecimento surge neste percurso como fator de integração entre o poder público e os catadores, sendo instrumento de inclusão dessa parte da população que contribui para uma distribuição e reutilização adequada dos resíduos

revista brasileira educação ambiental 
sólidos. A instalação planejada e paulatina desta nova realidade, na qual a coleta seletiva é um dos elementos, é a estratégia mais eficaz por parte do poder local na disposição desse processo.

Segundo Effting (2007), a importância da temática ambiental sobressaise na coleta seletiva, assim, a Associação de Catadores caracteriza-se em um espaço privilegiado na implementação dessas atividades que busca formas de sensibilizar a sociedade e valores que conduzam a uma convivência harmoniosa com o ambiente e as demais espécies que habitam o planeta, tendo a clareza que a natureza não é fonte inesgotável de recursos, suas reservas são finitas e devem ser utilizadas de maneira racional, evitando o desperdício e considerando a reciclagem como processo vital. De acordo com o Movimento Nacional dos Catadores de Materiais Recicláveis - MNCR (2008), os catadores de material reciclável atuam no processo de coleta, de separação e venda de resíduos sólidos e os utilizam como forma de sobrevivência. Os materiais coletados são repassados aos atravessadores, denominados por esse movimento como aqueles que comercializam com os catadores, que, por sua vez, compram esses materiais e os repassa às empresas recicladoras, que os fazem chegar à indústria.

Nesse sentido, o presente estudo teve por objetivo analisar os processos de aprendizagem organizacional, constituídos no decorrer da trajetória de um grupo de catadores que fazem parte da Associação e a emergência da organização social desse grupo. Buscou-se também identificar os principais percursos da construção da organização, na transição da aprendizagem individual e coletiva desses sujeitos sociais como uma das formas de empoderamento. Analisar a aprendizagem organizacional, e identificar os elementos envolvidos e compreender a relação entre $o$ aprendizado e a construção de competências organizacionais. A partir do entendimento do processo de aprendizagem e de formação de competências, pode-se então, teorizar a respeito das implicações destes com o projeto organizacional. Dentre os principais desafios que se constituem na análise do processo de aprendizagem, está a conversão do conhecimento tácito em explícito nos níveis individual e organizacional, e a evidenciação de relações causais entre as ações e os resultados de desempenho positivos ou negativos obtidos pela associação, o que ocorre em função do alto grau de subjetividade das relações causais, intrínsecas ao processo.

\section{Referencial Teórico}

\section{Coleta Seletiva e suas Implicações Socioambientais}

O desenvolvimento tecnológico associado ao crescimento populacional e às constantes mudanças nos padrões de consumo, que continuamente provocam a redução do ciclo de vida dos produtos, têm provocado o crescimento da prática do desperdício e o aumento excessivo na geração de resíduos. De acordo com Silva e Joia (2008) a "geração, a coleta, o tratamento e a destinação 
final dos resíduos sólidos urbanos tornaram-se um dos problemas ambientais mais graves dos tempos atuais para as administrações municipais no Brasil'.

Reduzir as milhões de toneladas dos vários tipos de resíduos sólidos - e seus impactos - que nossa civilização produz diariamente e garantir o uso sustentável dos recursos naturais constitui-se em metas planetárias para o século XXI, para que se possa atingir um modelo de desenvolvimento socialmente includente, ambientalmente sustentável e economicamente sustentado (JACOBI; BESEN, 2006).

O crescimento da problemática ambiental associado à poluição do meio e ao desperdício de recursos tem alertado para a importância da revisão de conceitos e mudanças na postura quanto à preservação do meio, através da redução, reutilização e reciclagem de resíduos rotineiramente gerados, antes considerados inúteis e sem valor. Segundo Cavalcanti, Souza \& Alves (2011), nesse contexto, a coleta seletiva se apresenta cada vez mais como uma alternativa economicamente e ambientalmente sustentável, na medida em que, além de evitar o descarte inadequado de resíduos, gera renda para milhares de famílias de catadores através da venda do material para empresas que atuam com reciclagem.

As primeiras iniciativas organizadas de coleta seletiva no Brasil tiveram início em 1986. Destacam-se, a partir de 1990, aquelas nas quais as administrações municipais estabeleceram parcerias com catadores organizados em associações e cooperativas para a gestão e execução dos programas. Essas parcerias além de reduzir o custo dos programas se tornaram um modelo de política pública de resíduos sólidos, com inclusão social e geração de renda apoiada por entidades da sociedade civil (SILVA; JOIA, 2008).

A Lei 12.305/2010, que estabelece a Política Nacional de Resíduos Sólidos, define coleta seletiva como a "coleta de resíduos sólidos previamente segregados conforme sua constituição ou composição". A lei afirma que essa coleta é uma ferramenta relacionada à aplicação da responsabilidade compartilhada pelo ciclo de vida dos produtos, sendo dos municípios a responsabilidade por sua implantação com a participação de cooperativas ou outros tipos de associações formadas por pessoas físicas de baixa renda, catadoras de materiais reutilizáveis e recicláveis. A Secretaria do Meio Ambiente (2012) define materiais recicláveis como aqueles que podem ser transformados em um novo material, podendo englobar papéis, vidros, plásticos, metais e orgânicos. 
Jacobi e Besen (2006) afirmam que apesar da reconhecida importância da coleta seletiva para preservação do meio ambiente, apenas $6,4 \%$ dos municípios brasileiros possuem programas de coleta seletiva. No Brasil ainda é pouca a quantidade de lixo reciclável recuperado. De acordo com o Diagnóstico do Manejo de Resíduos Sólidos Urbanos/2006, realizado pelo Sistema Nacional de Informação sobre Saneamento, cada brasileiro produz em média 920 gramas de lixo sólido por dia, porém a quantidade de lixo reciclável recuperado, seja por coleta seletiva ou por catadores, é de apenas $2,8 \mathrm{Kg}$ por ano, por habitante (ZENKER, 2008).

Para Ribeiro e Besen (2007), a formação de parceria entre administrações municipais e cooperativas ou associações de catadores na gestão e implementação de programas de coleta seletiva, reduziram os custos dos programas e se tornaram modelo de política pública de resíduos sólidos, gerando renda e inclusão social. Porém, de acordo com Jacobi e Besen (2006, p. 94) o contexto socioeconômico e ambiental dessas parcerias não é considerado na dimensão que merece, embora tenham surgido há mais de dez anos e façam parte da realidade nacional, "sua aplicação não está totalmente consolidada $e$ não consegue integrar os milhares de catadores autônomos que continuam a atuar nas ruas dos grandes centros urbanos".

Os programas em parceria com catadores organizados enfrentam dificuldades de ordem técnica (falta de capacitação), organizacional (organização do trabalho e baixa implementação da prática cooperativista) e econômica (competição pelo material reciclável, ausência de remuneração pelos serviços prestados pelos catadores) e carecem tanto de inserção institucional com base em instrumentos legais que garantam sua continuidade quanto de indicadores que possibilitem seu monitoramento e aprimoramento na perspectiva da sustentabilidade socioambiental e econômica (RIBEIRO; BESEN, 2007).

Esses programas enfrentam, portanto, diversas dificuldades que põem em risco a sua manutenção. Jacobi e Besen (2006) apontam também os desafios relacionados à insegurança permanente das associações de catadores, dada à alta dependência da municipalidade e baixa cobertura de atendimento. Além disso, é verificada a dificuldade de adaptação dos membros aos fundamentos de gestão e disposições do sistema cooperativista (JACOBI et al., 2006 apud JACOBI; BESEN, 2006).

Ao afirmar a importância da coleta seletiva para o meio ambiente, a Secretaria do Meio Ambiente (2012) listou os seguintes benefícios do seu desenvolvimento: 
- Diminui a exploração de recursos naturais;

- Reduz o consumo de energia;

- Diminui a poluição do solo, da água e do ar;

- Prolonga a vida útil dos aterros sanitários;

- Possibilita a reciclagem de materiais que iriam para o lixo;

- Diminui os custos da produção, com o aproveitamento de recicláveis pelas indústrias;

- Diminui o desperdício;

- Diminui os gastos com a limpeza urbana;

- Cria oportunidade de fortalecer organizações comunitárias;

- Gera emprego e renda pela comercialização dos recicláveis.

De acordo com a Secretaria do Meio Ambiente (2012), a coleta seletiva funciona como um meio de educação ambiental na medida em que conscientiza a comunidade sobre os problemas de poluição causada pelo lixo e desperdício de recursos naturais. Vários atores de uma comunidade podem participar do processo de coleta seletiva, contribuindo e se beneficiando dos resultados. Segundo Silva e Joia (2008), essa conscientização e reconhecimento do cidadão quanto ao seu papel como corresponsável pelos problemas ambientais, irá influenciar diretamente nos seus hábitos e costumes, mudanças essenciais para que o desenvolvimento sustentável possa ser alcançado.

A coleta seletiva tem potencial, portanto, para gerar diversos benefícios tanto no que diz respeito à sensibilização ambiental quanto para a geração de renda e capacitação para os setores mais carentes. Santos e Deluiz (2009 apud FERREIRA et al., 2012), atentam que a própria formação de cooperativas constitui meios para capacitação e educação da população, afirmando que "é possível que no contexto da produção cooperativa e solidária, a educação popular encontre novos caminhos e alternativas de ação, onde o trabalho socialmente produtivo também seja educativo".

\section{Desenvolvimento e a Economia no processo de aprendizagem organizacional}

As frequentes variações dos requisitos de competitividade no mercado, decorrentes do processo de globalização, tem exigido das empresas uma busca contínua pela melhoria de desempenho tanto produtivo quanto organizacional, desenvolvendo produtos ou serviços de maior qualidade a custos menores. A competitividade, em decorrência ao seu crescimento irrestrito a inclusão em um contexto econômico cada dia mais globalizado, expos setores e regiões à forte concorrência por fatias do mercado (LAGES; TONHOLO, 2006 apud MORAES, 2008).

Assim, segundo Ferreira (2012), torna-se visível a necessidade de que as empresas fortaleçam a sua estrutura, conheçam seu ambiente organizacional interno, para que a partir do estabelecimento de sua eficácia operacional,

revista brasileira educação ambiental 
possam desenvolver suas capacidades e manterem-se competitivas no mercado.

Um ambiente em que a complexidade e a turbulência das relações socioeconômicas possuem uma dinâmica significativa requer um novo modelo organizacional que desenvolva as qualidades de ser flexível e integrado, ou seja, que desenvolva uma condição favorável à aprendizagem constante e permanente com vistas ao desenvolvimento das competências necessárias (ZANGISKI, LIMA E COSTA, 2009).

Tendo em vista a sua influência nos mais diversos aspectos para se alcançar desenvolvimento, na chamada "Era do Conhecimento", a informação vem desempenhando um papel cada vez mais de destaque no cenário econômico. Conforme McGee e Prusak (1994), o que determina o sucesso é o que você sabe e não o que você possui, ou seja, o diferencial de uma empresa em relação às demais será a forma que esta adquire, trata, interpreta e utiliza suas informações.

Drucker (1992 apud SANTOS; SANTOS, 2009) afirma que esta nova sociedade, através da difusão da informação e controle dos meios de comunicação, tem o conhecimento como fonte de desenvolvimento e riqueza. Os crescentes investimentos em Pesquisa e Desenvolvimento - P\&D, educação, treinamento e outros investimentos intangíveis, cresceram mais rápido do que os investimentos físicos na maioria dos países, evidenciando o papel estratégico do conhecimento (MANUAL DE OSLO, 1997 apud FERREIRA, 2012).

De acordo com Sequeira (2008), as mudanças civilizacionais sempre tiveram como base o conhecimento, atualmente, dada a grande mobilidade das pessoas e dos saberes, torna-se ainda mais importante refletir sobre sua crescente utilização. A revolução impulsionada pelo conhecimento atinge todos os setores, exigindo mudanças estratégicas e estruturais na gestão organizacional e suas relações, como requisito para adaptação às transformações (ROSSETTI et al., 2008).

Tendo em vista a sua influência nos mais diversos aspectos para se alcançar desenvolvimento, o conhecimento desempenha um papel cada vez mais destacado no cenário econômico. Aqueles que possuem maior quantidade e qualidade de conhecimento são os que têm maior probabilidade de conseguir as melhores posições econômicas em longo prazo.

\section{Conhecimento e suas Formas}

Diversos autores, ao discutirem a importância do conhecimento, apontam a necessidade de diferenciá-lo da informação. Segundo Drucker (1999 apud Beppler, 2009), informação é um dado coberto de importância e propósito, e o conhecimento representa o meio através do qual dados são transformados em 
informação. A informação mostra-se como o conhecimento codificado, sugerindo a ideia de "saber o quê". O conhecimento envolve a elaboração da informação e de vários outros recursos, resultando em "saber por que, como e quem" (JOHNSON; LUNDVAL, 2001, apud LASTRES et al., 2005; FERREIRA, 2012). O conhecimento se apresenta, portanto, um conjunto de informações com valor agregado.

Segundo Silva (2003), tomando como referência a informação, para ser competitivo o importante não é acumular uma grande quantidade de dados, e sim saber transformá-los em informações úteis, acumulando conhecimento. Informação e conhecimento atuam como elementos-chave da nova gestão empresarial, sendo de competência da gestão da organização a busca por formas mais eficazes de captação e disseminação dos mesmos (ANGELONI, 2005).

Davenport e Prusak (1998) afirmam que o conhecimento que normalmente está inserido nas práticas, processos e valores da organização, é gerado através das interações humanas inseridas em um contexto organizacional.

Conhecimento é uma mistura fluida de experiência condensada, valores, informação contextual e insight experimentado, a qual proporciona uma estrutura para a avaliação e incorporação de novas experiências e informações. Ele tem origem e é aplicado na mente dos conhecedores (DAVENPORT; PRUSAK, 1998).

Nonaka e Takeuchi (1997) afirmam que o conhecimento é criado por indivíduos, sendo o conhecimento organizacional obtido a partir da ampliação do conhecimento individual cristalizado como parte da rede de conhecimentos da organização. Segundo os autores, o conhecimento organizacional exige interação intensiva entre os membros da organização, derivando da conversão ou transformação do conhecimento tácito em explícito. O conhecimento tácito é dinâmico, armazenado na cabeça das pessoas, inerente ao contexto, difícil de ser formulado e compartilhado. Já o conhecimento explícito é aquele facilmente propagável em linguagem sistêmica e formal.

Segundo Sequeira (2008), em um uma dimensão epistemológica, a combinação entre o conhecimento tácito e explícito faz surgir quatro modos de conversão do conhecimento - socialização, externalização, combinação e internalização - através dos quais esses conhecimentos se difundem, em quantidade e qualidade, em um ciclo ascendente do indivíduo até à interação organizacional com 0 ambiente. Os quatro modos de conversão do conhecimento, também conhecido como modelo SECl, foram identificados por Nonaka e Tekeushi (1997) para explicar o processo de criação do conhecimento organizacional, que segundo os autores é processo em espiral que começa no nível individual e vai ampliando através de interações que cruzam fronteiras até chegar ao nível organizacional. 


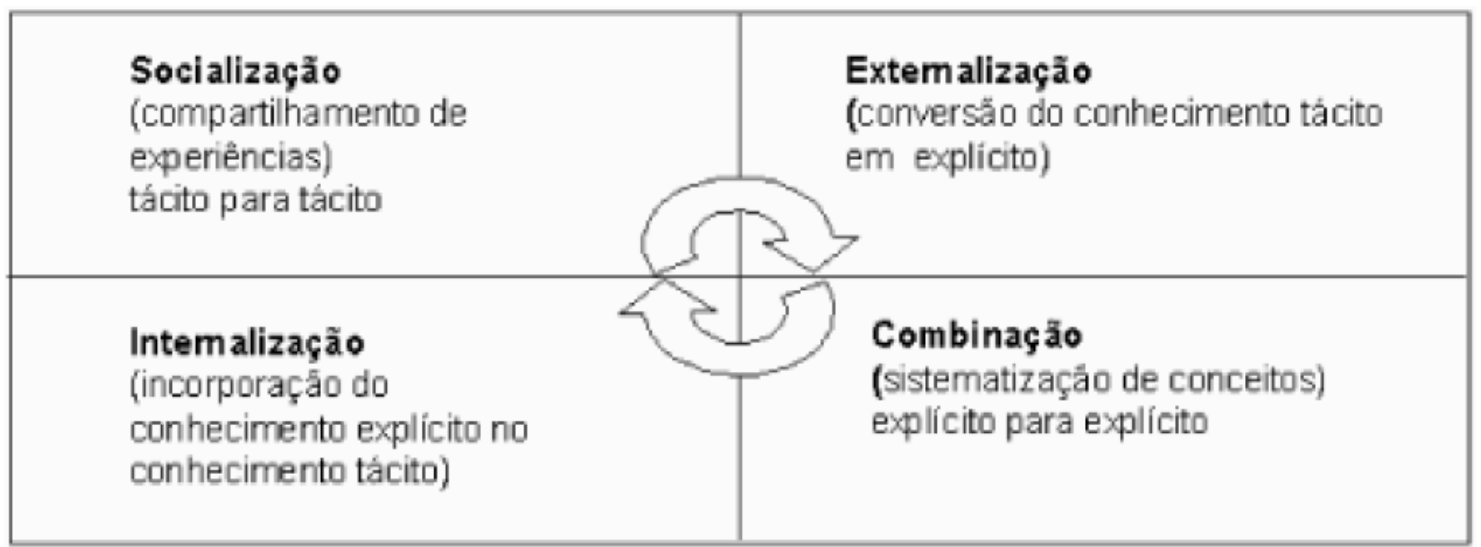

Figura 1: Modelo SECI. Fonte: Nonaka e Takeushi (1997)

Para se obter acesso a novas tecnologias e conhecimento é fundamental o contato pessoal e a interação entre os indivíduos. Lastres et al. (2005 apud Ferreira, 2012) definiu aprendizado como "o processo social de criação, aquisição, transformação, acumulação, difusão e compartilhamento (e também destruição) do conhecimento". Segundo Fleury e Fleury (1997), a aprendizagem é um processo de mudança decorrente de uma prática ou experiência anterior que pode ou não resultar em uma mudança de comportamento, podendo se desenvolver em diversos ambientes, entre os quais: escola, família e organização de trabalho.

Esse processo envolve diversos agentes, ocorrendo principalmente através da competência intrapessoal e de trocas interpessoais de conhecimento, necessitando de um ambiente de sinergia que propicie seu desenvolvimento (FERREIRA, 2012).

O aprendizado organizacional depende de práticas e de rotinas, de padrões de interação dentro e fora da empresa, e da capacidade de mobilizar conhecimento tácito individual e promover interações. Tal aprendizado pode ser estimulado por meio de um cuidadoso arranjo de práticas, rotinas e relacionamentos ou através de uma organização mais fluida e flexível na qual os indivíduos são incentivados a desenvolver novas ideias e formas de realizar as tarefas (MANUAL DE OSLO, 1997 apud FERREIRA, 2012).

Existem diversos meios para obtenção de conhecimento, variando conforme a forma de aprendizagem. Segundo Fleury e Fleury (1997), existem seis formas de aprendizagem: 
1. Aprender ao operar (learnig by doing) - ocorre à medida que o processo de produção responde às atividades desempenhadas;

2. Aprender pela mudança (learning by changing) - aprendizado se baseia nas mudanças operacionais que ocorrem dentro da organização;

3. Aprender pela análise do desempenho (system perfomance feedback) dependerá da existência de mecanismos de análise do desempenho da produção aplicados pela organização;

4. Aprender ao treinar (learning through training) - forma mais simples de aprendizado, obtido através do treinamento formal;

5. Aprender por contratação (learning by hiring) - obtenção de conhecimento e habilidades através da contratação de pessoal especializado que transfere seu conhecimento para o ambiente de trabalho contratante;

6. Aprender por busca (learning by searching) - derivada de uma transferência tecnológica, da capacidade de decodificar, entender e aplicar informações.

O conhecimento, portanto, é criado a partir da informação, utilizando-se da aplicação de modelos mentais e processos de aprendizagem dos indivíduos (ROSSETTI et al., 2008). Nesse contexto, de constante difusão e mobilidade do conhecimento, são fatores críticos ao sucesso para quase todas as organizações, a obtenção, síntese e compartilhamento de ideias e experiências (DRUCKER, 2000 apud CARVALHO; BOLSONI, 2011).

\section{Importância e Dificuldades da Aprendizagem Organizacional}

O conhecimento precisa estar acessível e ser utilizado como um dos recursos mais importantes da organização, sua mera existência será de pouco valor (ROSSETTI; MORALES, 2007).

O conhecimento tornou-se, por meio de sua identificação, criação, compartilhamento e valorização, um dos principais instrumentos para a competitividade das organizações, considerando-se relevantes tanto à gestão do conhecimento explícito, como a do conhecimento tácito e a criação de novos conhecimentos (TAKEUSHI, 1998 apud GARCIA; POSSAMAI, 2009).

A fim de se garantir a disseminação desse conhecimento na organização de forma sistêmica e eficiente para a obtenção de vantagens competitivas, tornase fundamental a implementação de técnicas para o gerenciamento do mesmo. Segundo Rossetti et al (2008), o ritmo acelerado de mudanças e inovações tecnológicas tem exigido a identificação e gestão inteligente não só dos fatores tradicionais de produção, mas do conhecimento dos indivíduos que compõem as organizações. É fundamental que em uma organização sejam conhecidos os 
recursos que, além de geradores de bens e serviços, sejam responsáveis pela agregação de valor (BEPPLER, 2009).

Nesse contexto, a gestão do conhecimento surge como um conjunto de estratégias e processos de administração, identificação, exploração e alavancagem de todos os tipos de conhecimento existentes na organização, bem como, aquisição de ativos de conhecimento e desenvolvimento de oportunidades para ajudar a empresa a competir (JARRAR, 2002 apud ROSSETTI et al., 2008). De acordo com Davenport e Prusak (1998), a gestão do conhecimento abrange a codificação, controle e compartilhamento do conhecimento explícito e tácito da organização.

Sequeira (2008, p. 9) afirma que a "transferência do conhecimento sucede de forma natural no cotidiano das organizações sendo importante que a gestão do conhecimento possa intervir dando-Ihe alguma formalidade, mas não o asfixiando". Beppler (2009) afirma que ao aplicar um modelo ou políticas de gestão do conhecimento, o gestor precisa levar em consideração a possibilidade de resistência ao processo de transferência do conhecimento, uma vez que envolve perda de poder. Segundo Mattos e Goulart (2012), o processo de geração de informação e conhecimento é influenciado por diversos fatores como cultura e representações sociais, sendo resultado de processos individuais e coletivos.

O sistema de conhecimento encontra-se envolvido por um conjunto de práticas sociais no qual o conhecimento individual está localizado, necessitando da interação dialética entre os indivíduos e o contexto no qual estão inseridos (SEQUEIRA, 2008).

De acordo com Rossetti et al. (2008), a cultura se apresenta como um dos fatores mais influentes no desenvolvimento de práticas de gestão do conhecimento, tanto na inibição quanto na promoção das mesmas, sendo de grande relevância para a organização, se atentar as suas diferentes culturas e/ou atores das redes de trabalho, permitindo que todos os componentes realizem seus objetivos. Assim, o conjunto de valores e crenças de uma organização apresenta-se como um dos fatores de maior impacto no ciclo de aprendizagem organizacional, podendo representar barreiras ao processo de formação de competências e aprendizagem organizacional, cuja eliminação é crucial para efetividade do processo (ZANGISKI et al., 2009).

As barreiras à aprendizagem podem existir em vários estágios do ciclo de aprendizagem, como nos níveis da ação, da reflexão e da disseminação do conhecimento, logo, seu diagnóstico não é um processo simples e pode exigir o envolvimento de todas as pessoas da organização (NADLE et al., 1992 apud ZANGISKI et al., 2009). 
Qualquer processo que envolva troca de conhecimento pode sofrer interferência de fatores culturais, de identidade e poder, podendo a estrutura organizacional ser utilizada como ferramenta de retenção e disseminação do conhecimento (BEPPLER, 2009). A gerência precisa estar atenta aos "aspectos ligados à etnia, culturas e línguas, de modo a capitalizar o conhecimento de todos os atores" (ROSSETTI et al., 2008, p. 69).

Drucker (1993 apud Curado, 2006) defende que, na organização, como meio para obtenção de resultados econômicos e sociais, os gestores precisam de mais conhecimento sobre o conhecimento. A gestão do conhecimento deve ser vista como um meio para alcance dos objetivos estratégicos de uma organização, não como um fim, devendo o gestor ter sempre em vista que o objetivo de uma organização é ser eficiente e eficaz (BEPPLER, 2009).

Assim, esta pesquisa se delineia com base no conceito de aprendizagem organizacional defendido por Nonaka e Takeuchi (1997), para os referidos autores, "(...) a aprendizagem em organizações, ainda, é definida como a capacidade de aprender integrada à formação de infraestrutura para sustentar os processos de aprendizagem, bem como aos diversos conhecimentos, habilidades, valores e insight'. Ao mesmo tempo, o conhecimento pode ser criado e reformulado com base em elementos que tenham flexibilidade e qualidade, já que a aprendizagem pode ocorrer mais em razão das experiências cotidianas e do "uso de uma linguagem metafórica que programas formais". Essa corrente teórica destaca a memória organizacional como recurso importante para a aprendizagem, e o seu objetivo é focar na adaptação organizacional às mudanças ambientais externas e internas, como um processo contínuo e sem interrupções.

\section{Metodologia da Pesquisa}

A metodologia de pesquisa utilizada neste trabalho está fundamentada em uma abordagem qualitativa de natureza teórico-empírica. Baseada em Deslandes e Minayo (2011, p. 21), "a pesquisa qualitativa responde a questões muito particulares, pois trabalha com o universo dos significados, dos motivos, das aspirações, das crenças, dos valores e das atitudes". Para as autoras, a pesquisa qualitativa responde a questões muito específicas. Por se ocupar, nas Ciências Sociais, e no caso dessa pesquisa, com a construção de um discurso que aponta para alguns pontos de vista do sujeito entrevistado que não pode ser quantificado. Essa junção de fenômenos humanos é entendida aqui como parte da realidade social, pois o ser humano se distingue não só por agir, mas por pensar sobre o que faz e por interpretar suas ações dentro e a partir da realidade vivida e partilhada com seus semelhantes.

Assim sendo, as autoras afirmam que a pesquisa qualitativa se preocupa com a compreensão interpretativa da ação social. Dessa forma, a abordagem qualitativa atua levando em conta a compreensão, a inteligibilidade dos fenômenos sociais e o significado e a intencionalidade que the atribuem os atores. 
Nesse contexto, a escolha da pesquisa qualitativa possibilitou a utilização de outras perspectivas teóricas e metodológicas, com a finalidade de melhor conhecer e validar o estudo realizado. Assim, foi possível recorrer à triangulação teórica que pode ser entendida como o uso de várias perspectivas diferentes na análise do mesmo corpus defendido por Cliford (1998). Para instigar a discussão teórico-metodológica com características que segundo o referido autor, norteiam o estudo da prática do discurso, e facilita o mergulho da pesquisa no território linguístico para alcançar quatro modos distintos de leitura de um corpus: a narração, a descrição, a interpretação e a compreensão.

\section{Sobre a coleta de dados}

A pesquisa foi realizada na sede da Associação por meio de entrevista aberta à fundadora da mesma, com a presença de alguns associados. Foi dividida em três etapas: reconhecimento do ambiente, entrevista e registro fotográfico. A divisão do trabalho foi feita em três momentos, isso se justifica pela necessidade do desenvolvimento de um vínculo de confiança entre os pesquisadores e o sujeito da pesquisa.

Reconhecimento do ambiente: na visita ao ambiente onde os resíduos sólidos são acumulados, para em seguida serem separados, procurou-se tanto conhecer o ambiente quanto estabelecer os contatos iniciais com a entrevistada. Observou-se no lixão um cenário onde os seres humanos trabalhavam, muitas vezes, envolvidos em diferentes ações, tais como: separação dos resíduos provenientes da informática, papéis, papelões, vidros, garrafas pet, plásticos etc. Além de observar as condições de trabalho existentes na associação, foi possível conhecer superficialmente as pessoas que labutam na mesma. Através desse contato com o sujeito da pesquisa, pôde-se efetuar a triagem das perguntas que comporiam definitivamente o roteiro da entrevista.

Entrevista: narrativa coletada mediante entrevista aberta e semiestruturada, tendo um roteiro como fio condutor de toda a conversa. Participou deste estudo 01 (uma) mulher que foi a fundadora da entidade, mesmo estando presentes outras associadas, o nosso foco foi ouvir a precursora desse processo, já que tínhamos como objetivo analisar o processo de aprendizagem organizacional da gestão, na administração das ações da coleta seletiva na associação. A entrevistada alega que na Associação atuam cerca de 20 catadores e catadoras, a maioria é composta por mulheres com média de idade entre 25 e 33 anos.

Com tal expediente, procurou-se dar a maior liberdade possível ao sujeito, para responder as perguntas contidas no roteiro e aos poucos essa ação foi se caracterizando em um diálogo espontâneo. Recordamos que a presença de outros indivíduos no decurso da entrevista pôde influenciar os relatos da depoente tanto lhe impedindo, indiretamente - por causa da sua simples presença, de expressar o que pensa e/ou sente diante do questionamento que Ihe foi feito, quanto interferindo diretamente, fazendo comentários ou sugestões sobre as respostas dadas pela entrevistada. A referida ocorrência foi verificada 
durante a visita. Porém, não se pôde deixar de notar que a presença de outras pessoas se fez essencial para compreender os processos de interação coletiva em que as representações sociais são produzidas, reproduzidas e modificadas.

Utilizamos a técnica de interpretar o discurso de abertura do processo de comunicação e análise das narrativas da relação dialógica como epistemologia do processo de encontro entre pesquisadores e pesquisada. A fundadora da Associação narrou sua trajetória de vida, descreveu e argumentou sobre fatos, situações, problemas e momentos significativos.

Registro fotográfico: o ambiente da Associação foi fotografado não apenas para ilustrar o trabalho, mas também, com a finalidade de identificar elementos capazes de auxiliar 0 entendimento de determinados comportamentos apontados pela fundadora da Associação aqui estudada.

\section{Contextualização dos resultados}

Para Flick (2009, p.276), a análise dos dados constitui a "essência da pesquisa qualitativa" e assevera que a circularidade representa um de seus pontos fortes, tendo em vista que obriga o pesquisador a refletir constantemente sobre o processo de pesquisa e sobre etapas específicas, à luz das outras etapas.

Nessa perspectiva, no presente estudo, foi adotado, o que Alencar (2007, p.50) afirma ser "Modelo interativo em pesquisa". Tal modelo circular permite análise parcial realizada como parte integrante da coleta de dados. De modo que, essas análises fornecem novos elementos para a continuidade da investigação, estabelecendo uma constante interação entre pesquisador e objeto de pesquisa.

A Associação iniciou em 15/05/1999, completou 15 anos, tem como sede um grande espaço murado e uma área coberta que serve de escritório. De acordo com a entrevistada, o Movimento Nacional financia os cursos sobre a qualidade de vida dos catadores, com o objetivo de fortalecê-los.

De acordo com a mesma, no início da Associação, eram feitos trabalhos educativos, tais como: o Circo da Luz nas escolas, com o objetivo de atrair a atenção e sensibilizar o pessoal a ajudar a associação por meio da divulgação das finalidades da mesma. "(...) tínhamos ateliê, mas acabou tudo isso, a aceitação do artesanato era pouca, paramos de desenvolver". Assim, a ideia da Associação não é só reciclar, mas fazer reutilização e trabalho educativo. $\mathrm{Na}$ opinião da fundadora é preciso ter todo o processo de educação ambiental, já que, associados foram adquirindo por meio de oficinas e participação em eventos repertório que facilitam o desenvolvimento do trabalho.

A partir desse contexto, procuramos analisar as informações obtidas por meio da visita e da observação, e começamos a examinar a visão de organização da Associação por meio da sua fundadora e idealizadora. Para tanto, procurou-se, mediante a análise de sentimentos auto atribuídos, expectativas de vida, conceitos referentes à mão-de-obra, o repertório de

revista brasileira educação ambiental 
conhecimentos mapeados na instituição, além das relações que se estabelecem entre essas variáveis, estudar a maneira como a entrevistada vê o mundo e a relação entre ambiente, tecnologia e sociedade.

A percepção da organização desse grupo social foi se revelando na narrativa da fundadora. Algumas palavras revelam o percurso da vida desses sujeitos que emergiam constantemente na fala da entrevistada, revelando por vezes uma conotação mais negativa, tais como: “(..) o pessoal está aqui por necessidade"; "(...) fui ao lixão chamar o pessoal para trabalhar na coleta seletiva, mas, havia muita resistência por ganhar pouco"; "(...) sofremos muito preconceito, alguns associados tinham vergonha, e não juntava o material, isto é preconceito social'. Aos poucos essa conotação foi sendo substituída. Por exemplo, a palavra "preconceito social", que era utilizada para definir ações sofridas pelo sujeito da ação do (a) catador(a), foi substituída pelo termo "oportunidade de trabalho". Para melhor compreensão da substituição da palavra preconceito social, pela oportunidade, destacamos o conceito de preconceito e sua forma de expressão, a discriminação, apoiados nas representações sociais que foram definidas como "entidades quase tangíveis [...] que circulam, cruzamse e se cristalizam incessantemente através de uma fala, um gesto, um encontro" (MOSCOVICl, 1978: 41).

Nesse contexto, Amado (2005) contribui quando defende que essas formas de preconceito eram entendidas como formas de exteriorização de um "conhecimento socialmente compartilhado" a respeito dos "fenômenos" inerentes ao "mundo de cada indivíduo", bem como, em constante renovação através das interações sociais. Observando a definição proposta pelo autor, percebe-se que o conceito de representação social foi enriquecido por meio do emprego da ideia "sobre a identidade social, cujo pressuposto é que a atribuição de características negativas aos membros do grupo seria consequência do processo de categorização social cuja divisão básica seria o 'nós' e o 'eles'. A discriminação teria, como função básica, a manutenção de uma identidade ancorada nas pertenças sociais cuja valência teria que ser positiva" (LIMA; PEREIRA, 2004, p.3 e 212).

Nesse caso, a fundadora da Associação descreve as atividades da Associação como uma oportunidade, porque para a mesma é importante os associados serem contratados pela prefeitura e terem salários fixos, já que para ela: "(...) fazemos o trabalho deles, nada mais justo que sejamos contratados... mas, essa vai ser outra luta".

A fundadora foi questionada sobre a sua formação, se estudou? Até que ano? Onde? Por que optou pela associação? Aconteceu formação continuada na associação? Todas essas questões tinham a finalidade de mapear as aprendizagens individuais da fundadora antes e depois da associação, e como a mesma conseguiu transformar e/ou transferir essas aprendizagens para 0 coletivo, e principalmente, qual o elemento mínimo estrutural que a mesma elaborou neste processo gerencial. 
A pesquisada informou que estudou até a $5^{\text {a }}$ série (atualmente denominada $6^{\circ}$ ano do ensino fundamental), começou a participar de seminários e congressos no Brasil inteiro depois da Associação, informou também que o Ministério Público cobre todas as despesas, no entanto, não conhecem o trabalho desenvolvido pela instituição.

Nesse ponto da trajetória, a fundadora passou a pensar e refletir sobre os caminhos, os conflitos e as lutas que os levaram à construção de novos caminhos pela busca da superação dos processos de exclusão presentes na identidade desse coletivo.

De acordo com a mesma, todos os associados têm oportunidade de participar de cursos em São Paulo e Curitiba, fazem revezamentos para que todos tenham o mesmo direito de adquirir conhecimentos. Quanto à formação inicial diz: "(...) incentivo o pessoal a continuar os estudos, mas eles não querem". "(...) uma senhora faz Educação de Jovens e Adultos - EJA, o quarto nível'; "(...) quanto a mim só preciso de um diploma, sou formada na vida". (entrevista, 2014)

A informalidade do processo de diagnóstico de identificação de necessidades da gestão do conhecimento foi percebida pela fala da fundadora, conforme o depoimento:

(...) fui incentivada a criar a associação de catadores por Valdemir Freire, e todas as discussões começaram na minha casa, fazíamos as reuniões sempre pensando na preservação do ambiente, pensando na sustentabilidade. (...) as Universidades, por meio de projetos têm ajudado muito, pena que quando encerram os projetos muitos se afastam, hoje só têm dois desses alunos que continuam colaborando, mas, consegui mais alguns recursos, inclusive as prensas de papel e papelão, foram adquiridas por meio dos projetos (Entrevistada, 2014).

A pesquisa explorou também a prática da organização no registro de experiências de aprendizagem. Nesse sentido, Choo (2003) defende que acontece por meio da aquisição e uso da informação. Constatou-se que a maioria dos processos de assimilação de conhecimento acontece de maneira informal, sendo, portanto, pouco comum o registro de experiências e melhorias. No entanto, foram encontrados na pesquisa documental (certificados de participação em cursos, seminários, fóruns e congressos) indícios voltados para a preocupação de registros de experiências de aprendizagem, o que evidencia a distância entre prática e discurso: 
(...) a maioria deles não estudaram, os que estudaram, fizeram no máximo até a $6^{\underline{a}}$ série do Ensino Fundamental. (...) aprendemos a separação de materiais com outras cooperativas e experiências do dia-a-dia. (...) o pessoal da Universidade, no período do projeto, fez treinamento (artesanato, reciclagem, de óleo e demais materiais), chamaram um pessoal de Natal, aprendiam a fazer para repassar para a associação (tinham apostilha), isso durou mais ou menos 4 (quatro) anos. (...) Eles têm conhecimento quanto o que pode ser feito com o material, mas não fazem o tratamento (Entrevistada, 2014)

Referindo-se aos impactos que o lixo pode causar ao meio ambiente constatou-se que a entrevistada tem conhecimento tácito sobre a temática, quando defende que a grande dificuldade e a deficiência da população local no que concerne a educação ambiental. Critica a forma como as escolas trabalham a educação ambiental, "(...) os alunos vêm e compram garrafas (só para ganhar nota). Eram para juntar e ajudar a associação". Nesse sentido, a mesma comenta que a sociedade só percebe o lixo como problema quando o mesmo está visível. E este se dispensado de forma incorreta acaba por poluir esteticamente os logradouros. O acúmulo do lixo contribui para a caracterização de uma cidade suja e uma sociedade sem consciência dos problemas que podem ser gerados em atividades diárias da humanidade. Esses impactos podem ser identificados na saúde, poluição ao meio ambiente e na visão estética das vias públicas. Além disso, resíduos sólidos não dispensados em locais adequados acabam por promover a proliferação de vetores transmissores de doenças.

\section{Considerações Finais}

Os resultados da pesquisa apontam para dois níveis em que se localizam desafios e limitações gerais na Associação de Coleta Seletiva. Em um primeiro momento os desafios e limitações mais marcantes estão no âmbito das características da própria associação. Em um segundo nível, identificou-se desafios e limites localizados nas dificuldades experimentadas pela associação de catadores, no que diz respeito à zona fronteiriça entre a organização das aprendizagens e a gestão do conhecimento.

No âmbito das características da organização das aprendizagens e da gestão, já que falar em gestão implica em estabelecer ações intencionais. $\mathrm{Na}$ Associação, identificou-se desafios e limitações de ordem técnica, econômica, e administrativa. Percebe-se que a falta de reconhecimento institucional interfere nas várias características da gestão e surge como a fragilidade mais marcante no processo administrativo. Diante da fragilidade institucional, a Associação encontra dificuldades em coordenar e articular as ações conjuntas entre a Associação e as instituições parceiras, o que conduz a fragmentação e descontinuidade das ações e a instabilidade financeira. 
De acordo com o relato da entrevistada "A instabilidade da Associação, provoca uma rotatividade de associados". No que se refere aos aspectos experimentados pela Associação, verificou-se pelos resultados obtidos que muitas das dificuldades de gestão enfrentadas pela instituição encontram-se localizadas no âmbito de ação e gestão da própria Associação. Contudo, é preciso evidenciar as fragilidades vividas pela Associação e pelos sujeitos que a compõe.

Além de ter que enfrentar a dificuldade vivida cotidianamente, da escassez de recursos financeiros, de equipamentos e infraestrutura, embora seja uma das duas associações apoiadas, oficialmente, pela Prefeitura Municipal, pode-se afirmar, de acordo com relato da entrevistada, que a baixa escolaridade e o desconhecimento de tecnologias mais adequadas constituemse em evidentes restrições ao alcance de resultados mais consistentes.

Acerca das dificuldades vividas em relação à organização das aprendizagens e conflitos internos, a fundadora reconhece suas limitações e afirma, ainda, terem um longo caminho a trilhar. Sabe-se, no entanto, que parte dos desafios impostos à gestão da Associação é gerada pela ideia da própria sobre o coletivo da associação, mesmo esta tendo a consciência do seu papel indispensável e que a sua formação é importante para o desenvolvimento da instituição. A mesma demonstra, apesar de não ter uma formação acadêmica, um repertório de conhecimentos vasto (aprendizagem individual), no entanto, aparentemente não consegue trazer esses conhecimentos para contribuir com a organização do coletivo.

Capelle (2003) define que todo o processo de gestão, desde a etapa de planejamento até sua operacionalização, com ações e metas mensuráveis, sem deixar de lado as etapas de avaliação e monitoramento, para sua adequação às necessidades da população local, com controle social, nas tomadas de decisão, contribui para o reconhecimento da associação e da coleta seletiva como estratégia válida de geração de trabalho e renda e inclusão social dos catadores envolvidos. Além disso, promove condições favoráveis ao seu processo de institucionalização.

As discussões acerca da organização das aprendizagens e da gestão do conhecimento situam-se dentro de um debate como propositor da organização de trabalho e renda, inclusão social e cidadania aos catadores envolvidos. Por enquanto, merece notar que o alcance e os resultados obtidos são limitados.

As evidências analisadas a partir das narrativas da idealizadora da Associação permitiram concluir as seguintes concepções: organização das aprendizagens e gestão do conhecimento como modelos administrativos, não coadunam com a identidade da instituição pesquisada, percebemos que todas as aprendizagens se dão informalmente, e o modelo de gestão preconizado é o "modelo de trabalhar" com as condições que nos são oferecidas. Portanto, não existe intencionalidade no processo, menos ainda mapeamento das competências individuais e/ou coletivas. Nesse processo foi evidenciada a vulnerabilidade educativa e econômica desses sujeitos sociais mesmo inseridos 
nas organizações, e principalmente as dificuldades que são encontradas nos processos de sua formação política, social e ambiental como participantes de uma Associação de Coleta Seletiva e a construção de identidades individuais e coletivas, como grupo cultural que fazem parte catadores (as) de material reciclável (trabalhadores e/ou trabalhadoras).

A efetividade e sustentação da Associação, ao longo do tempo, exigem de todos os atores envolvidos o esforço de repensá-la em sua essência. $E$ finalmente, os rumos da Associação de Coleta Seletiva dependem também da mudança do governo municipal em curso e da orientação das ações a serem adotadas a partir de então.

\section{Referências}

AMADO, V.A., FREITAS, S.M., IENO, G.; CAMINO, L. Ocupações rurais: capacidade de mobilização e contradições internas do movimento dos trabalhadores rurais sem-terra. In TORRES, A.R.R., LIMA, M.E.O.; COSTA, J.B. (org.). A psicologia política na perspectiva psicológica: o estudo das atividades políticas (Vol. I; pp. 111-138). Goiânia: UCG, 2005.

ANGELONI, M.T. Organizações do Conhecimento: Infraestrutura, Pessoas e Tecnologias. 1를 edição, São Paulo: Saraiva, 2005.

BEPPLER, L.N. (2009) Gestão do conhecimento empresarial. Disponível em: $<$ http://www.batebyte.pr.gov.br/modules/conteudo/conteudo.php?conteudo=135 $\underline{0}>$. Acesso em 06 mai. 2014.

BRASIL, 2010. Lei no 12.305/2010 - Institui a Política Nacional de Resíduos Sólidos. Presidência da República, Brasília. Disponível em: $<$ http://www.planalto.gov.br/ccivil 03/ ato2007-2010/2010/lei/l12305.htm>. Acesso em: 05 jun. 2014.

CAPELLE, M.C.A,; MELO, M.C.O. L; GONÇALVES, C.A. Análise de conteúdo e análise de discurso nas ciências sociais. Revista de Administração da UFLA, Lavras, v.5, n 1, p. 69-85, jan./jun., 2003.

CARVALHO, E.N.; BOLSONI, E. A Influência da Gestão da Informação no Desenvolvimento Estratégico da Organização: Um Estudo de Caso da Empresa Estrela H. Revista Científica Indexada Linkania Júnior, v.1, n. 1, set./out. 2011.

CAVALCANTI, C.R.; SOUZA, F.C.S.; ALVES, G.S. Estudo do Gerenciamento da Coleta Seletiva dos Resíduos Sólidos no Município de Mossoró-RN. HOLOS, São Paulo, ano 27, v. 4, mai./jun. 2011.

CHOO, C.W. A Organização do conhecimento: como as organizações usam a informação para criar significado, construir conhecimento e tomar decisões. São Paulo: Senac, 2003.

CLIFORD, J. A experiência etnográfica-antropologia e literatura no século XX. Rio de Janeiro: UFRJ, 1998. 
CURADO, C.M.M. O efeito mediador das estratégias de gestão de conhecimento entre componentes do capital intelectual: um estudo realizado na indústria bancária portuguesa. Dissertação (Doutorado em Economia e Gestão) Instituto Superior de Economia e Gestão, Universidade Técnica de Lisboa, Lisboa, 2006.

DAVENPORT, T.H.; PRUSAK, L. Conhecimento empresarial. Rio de Janeiro: Campus, 1998.

DUARTE, A. Novos Consumos e Identidades em Portugal - Uma perspectiva Antropológica. Tese de doutorado, junho 2007, Disponível via $</ /$ repositório.iscte.pt/bitstream/10071/628/1/TESE.pdf> Acesso em: 20/06/2014.

EFFTING, T.R. Educação Ambiental nas Escolas Públicas: Realidade e Desafios. Marechal Cândido Rondon, Monografia. 2007.

FERNANDES, A.C. Conhecimento e Aprendizagem Organizacional em Perspectiva. Anais do SEMINÁRIO BUSINESS IN THE KNOWLEDGE ERA: NOVOS MODELOS DE NEGÓCIOS NA SOCIEDADE DO CONHECIMENTO, 1., 1998, Rio de Janeiro. Rio de Janeiro: COMPETENET, 1998. Disponível em: <http://www.competenet.org.br/evento/amarildo.pdf>. Acesso em: 15/06/2014.

FERREIRA, A.R.; CAMACHO, R.G.V.; ALCANTARA NETO, A.Q. Avaliação e Diagnóstico Ambiental dos Resíduos Sólidos Gerados no Município de Mossoró/RN. GEOTEMAS, Pau dos Ferros, v. 2, n. 2, jul./dez. 2012.

FERREIRA, V.E.S. Análise das Vantagens Competitivas Decorrentes da Gestão da Inovação e Conhecimento no APL de Moda Íntima de Frecheirinha - CE. Monografia (Graduação em Ciência e Tecnologia) - Pró-reitoria de Graduação - Departamento de Agrotecnologia e Ciências Sociais, UFERSA, Mossoró, 2012.

FLEURY, A.C.C., FLEURY, M.T.L. Aprendizagem e Inovação Organizacional: as experiências de Japão, Coréia e Brasil. 2 ed. São Paulo: Atlas, 1997.

FLICK, U. Introdução à pesquisa qualitativa. 3.ed. Tradução de Joice Elias Costa. Porto Alegre: Artmed, 2009. 405 p. Título original: Qualitative Sozial for scchung.

GARCIA, M.A.; POSSAMAI, O. Gestão do Conhecimento no Processo de Desenvolvimento de Produtos: Modelo para a Identificação dos Fatores Críticos de Sucesso. Anais do XXIX Encontro Nacional de Engenharia de Produção. Salvador, $2009 . \quad$ Disponível em: $<$ http://www.abepro.org.br/biblioteca/enegep2009 tn sto 091615 13019.pdf> . Acesso em 06 mai. 2014.

JACOBI, P.R.; BESEN, G.R. Gestão de Resíduos Sólidos na Região Metropolitana de São Paulo. São Paulo em Perspectiva, São Paulo, v. 20, n. 2, abr./jun. 2006.

LIMA, M.E.O.; PEREIRA, M.E. (org.) Estereótipos, preconceitos e discriminação: perspectivas teóricas e metodológicas; Salvador: EDUFBA; 2004.

revista brasileira educação ambiental 
MATTOS, M.C.; GOULART, I.B. Da Possibilidade de uma GIC Ampla: Reflexões Iniciais Entre a Ciência da Informação e a Psicologia Social. Perspectivas em Gestão \& Conhecimento, João Pessoa, v. 2, n. 2, jul./dez. 2012.

MCGEE, J.; PRUSAK, L. Gerenciamento Estratégico da Informação. 14 ed. Rio de Janeiro: Elsevier, 1994.

MORAES, S.C.S. Análise da Competitividade de um Aglomerado Produtivo pelo Viés do Empreendedorismo: Uma Proposta Metodológica. Dissertação (Mestrado em Engenharia de Produção) - Programa de Pós-Graduação em Engenharia de Produção - Departamento de Pesquisa e Pós-Graduação, UTFPR, Paraná, 2008.

MOSCOVICI, S. A representação social da psicanálise. Rio de Janeiro: Zahar; 1978.

MOURA, A.S. (org.). Políticas públicas e meio ambiente: da economia politica às ações setoriais. Recife: Fundação Joaquim Nabuco, Editora Massanga, 2012.

NONAKA, I.; TAKEUCHI, H. Criação do Conhecimento na Empresa: como as empresas geram a dinâmica da inovação. Rio de Janeiro: Campus,1997.

RIBEIRO, H.; BESEN, G.R. Panorama da Coleta Seletiva no Brasil: Desafios e Perspectivas a Partir de Três Estudos de Caso. INTERFACEHS, São Paulo, v. 2, n. 4, ago. 2007.

ROSSETTI, A. A Organização Baseada no Conhecimento: Novas Estruturas, Estratégias e Redes de Relacionamento. Ci. Inf, Brasília, v. 37, n. 1, p. 61-72, jan./abr. 2008.

ROSSETTI, A.G.; MORALES, A.B.T. O Papel da Tecnologia da Informação na Gestão do Conhecimento. Ci. Inf, Brasília, v. 36, n. 1, p. 124-135, jan./abr. 2007.

SANTOS S. E. V.; SANTOS J. S. S. (2009) Contribuições de um Sistema de Gerenciamento de Informações e Automação de Laboratório: Estudo de Caso em uma Empresa de Mineração. Anais do XXIX Encontro Nacional de Engenharia de Produção. Salvador, 2009. Disponível em: $<$ http://www.abepro.org.br/biblioteca/enegep2009 TN STO 091615 13621.p df> Acesso em: 18 mai. 2014.

SECRETARIA DO MEIO AMBIENTE. (2012). Coleta Seletiva: Na Escola, no Condomínio, na Empresa, na Comunidade, no Município. Disponível em: <http://www.lixo.com.br/documentos/coleta\%20seletiva\%20como\%20fazer.pdf>

. Acesso em 25 mai. 2014.

SEQUEIRA, B. Aprendizagem Organizacional e a Gestão do Conhecimento: uma abordagem multidisciplinar. Anais do VI Congresso Português de Sociologia. Lisboa, $2008 . \quad$ Disponível em: <http://www.aps.pt/vicongresso/pdfs/497.pdf >. Acesso em 06 mai. 2014.

SILVA, M.S.F.; JOIA, P.R. Educação Ambiental: A Participação da Comunidade na Coleta Seletiva de Resíduos Sólidos. Revista Eletrônica da Associação dos Geógrafos Brasileiros, Três Lagoas, ano 5, n. 7, mai. 2008. 
SILVA, W.D.F. Introdução à Gestão da Informação. 1aㅡ edição, São Paulo: Alínea, 2003.

ZANGISKI, M.A.S.G; LIMA, E.P.; COSTA, S.E.G. Aprendizagem Organizacional e Desenvolvimento de Competências: Uma Síntese a Partir da Gestão do Conhecimento. Produto \& Produção, Porto Alegre, v. 10, n. 1, p. 54-74, fev. 2009.

ZENKER, A.L. Lixo reciclável recuperado no país ainda é pouco, diz secretário, 2008. Agência Brasil. Disponível em: $<$ http://memoria.ebc.com.br/agenciabrasil/noticia/2008-08-27/lixo-reciclavelrecuperado-no-pais-ainda-e-pouco-diz-secretario>. Acesso em 25 mai. 2014. 